\title{
Personal Knowledge Management Capability of Apprentices in Malaysian Technical and Vocational Education and Training
}

\author{
Iszurin Sha'ari \\ Faculty of Information Management, Universiti Teknologi MARA (UiTM), \\ Selangor, Malaysia \\ E-mail: iszurin.phd.2019@gmail.com \\ Norliya Ahmad Kassim \\ Faculty of Information Management, Universiti Teknologi MARA (UiTM), \\ Selangor, Malaysia \\ E-mail: norliya@salam.uitm.edu.my \\ Kasmarini Baharuddin (Corresponding author) \\ Faculty of Information Management, Universiti Teknologi MARA (UiTM), \\ Selangor, Malaysia \\ E-mail: kas@uitm.edu.my
}

Received: November 9, 2017 Accepted: February 27, 2018 Published: March 5, 2018

doi:10.5296/ijld.v8i1.12123 URL: https://doi.org/10.5296/ijld.v8i1.12123

\begin{abstract}
The purpose of the study is to investigate the Personal Knowledge Management (PKM) capability of apprentices in a Technical and Vocational Education and Training (TVET) institute. This study was conducted at the Institut Latihan Perindustrian Kuala Lumpur (ILP-KL) due to its maturity and long existence in Malaysia's TVET landscape. A quantitative research survey method was employed and questionnaire was distributed to a sample of 234 apprentices of ILP-KL. Data gathered from the survey was analyzed using the Statistical Package for the Social Sciences (SPSS) application. The finding indicated an average mean
\end{abstract}


score of 3.901 for PKM capability. Differences on PKM capability were compared from the selected demographic group of gender, age, region of origin and education level. The results of Mann-Whitney $U$ Test and Kruskal-Wallis Test indicated that the perception on Personal Knowledge Management Capability (PKMC) differs among the age group. The findings in this study led to the notion that ILP-KL has positive room for improvement to be made further in its apprentices' personal knowledge management initiatives. The study is also able to furnish the institution with details on areas or dimensions that could be effectively strategized for improving initiative and efforts.

Keywords: Knowledge management, capability, apprentices, Technical and Vocational Education and Training (TVET)

\section{Introduction}

Knowledge Management (KM) is a concept and a term that arose approximately more than two decades ago, roughly in 1990. In the early days of the KM movement, Davenport (1994) offered the still widely quoted definition of knowledge management as the process of capturing, distributing, and effectively using knowledge. This definition has the virtue of being simple, stark, and to the point. A few years later, the Gartner Group created another second definition of KM, which is perhaps the most frequently cited one (Duhon, 1998) whereby knowledge management is a discipline that promotes an integrated approach to identifying, capturing, evaluating, retrieving, and sharing all of an enterprise's information assets. These assets may include databases, documents, policies, procedures, and previously uncaptured expertise and experience in individual workers. Both definitions share a very organizational and corporate orientation. KM, historically at least, is primarily about managing the knowledge of and in organizations (Kassim, Baharuddin \& Samad, 2016). Well-organized knowledge use improves competitive benefit and advances organizational success. Knowledge management (KM) has become increasingly important as organizations realize that efficient use of their enormous and diverse knowledge possessions and resources offer them with the capacity to innovate and take action to rapid varying consumer hopes (Satar, 2012). In today's era which is called knowledge era, organizations witness environments that get more dynamic and challenging day by day (Farshad \& Azizi, 2015).

Personal Knowledge Management (PKM) or also referred as Personal Information Management has become an interest in the study of knowledge management due to the management attributes of knowledge itself which is best accomplished by people; the movers and shakers of knowledge or the best knowledge manager (Jafari, Akhavan, \& Nikookar, 2013). This understanding leads to the importance of managing personal knowledge before delving into organizational knowledge management. Jafari, Akhavan and Nikookar (2013) iterated that the benefit of PKM is not only at individual level as the combination of PKM with KM organization would bring about powerful management of knowledge in and within organizational components. They also highlighted that PKM is a recent knowledge management subject being studied as previous researchers and scholars focuses the study of knowledge management at organizational level rather than studying how knowledge workers organize their knowledge at individual or personal level. PKM took to being a second fiddle 
in knowledge management (a subset of knowledge management) as opined by $\mathrm{Li}$ and $\mathrm{Li}$ (2009).

Having understood PKM's importance and position, it is imperative for us to know what Personal Knowledge Management is. Again, Jafari, Akhavan and Nikookar (2013) took the best of Frand and Hixon (1999) and Avery et al. (2001)'s description of PKM, and summarized that PKM refers to the process and strategy of individuals in expanding personal knowledge where the individuals organize information they obtained from learning or knowledge acquiring activities as a part of their own knowledge and in doing so individuals transform loose information fragments into systemic application information; turning information into useful knowledge. Thus PKM warrants for individuals to execute the process of (1) retrieving, (2) evaluating, (3) organizing, (4) collaborating, (5) analyzing, (6) presenting, and (7) securing information in their personal knowledge bank.

Malaysia has had its fair share in experiencing the apprenticeship system in its education and industrial sector. In the Asian region and also in its counterpart region around the world apprenticeship is best known and referred as "Technical and Vocational Education and Training" or "TVET". One of the areas that is seldom delved into when discussing TVET or apprentice, is the apprentice own ability and capability to manage learning via knowledge retention, retrieval and utilization or Personal Knowledge Management (PKM). No doubt that TVET institution might be equipped with state of the art technicalities in learning, however, if apprentice themselves do not manage what is learnt, such knowledge and skills might be lost from apprentice knowledge bank or memory. Therefore one of the issues that might contribute significantly to issues of apprentice's performance could be the ability of apprentices to retain, retrieve and utilize knowledge of learning (PKME) that formed the Personal Knowledge Management Capability (PKMC) of apprentice at TVET institutions.

The purpose and implementation of this study was ideated based on previous academic study that purported technical and vocational education and training (TVET) has been around for quite a significant period and has served well in providing countries and nations with the technical expertise required to catapult them in becoming great industrial countries and nations, however researchers noted that not much study has been geared as to research into the behavioural segment of the TVET world (Amin \& Ruhizan, 2014; Martins \& Meyer, 2012). In this respect, behavioural relates to aspects in TVETs people capability that includes capability of learning, managing knowledge and the likes. This study was embarked in trying to fill the vacuum and initiate a behavioural research on TVET prized asset; the apprentices. The results from this study would introduce or re-introduce personal knowledge management, provide feedbacks, inputs and beneficial information to TVET institutions in Malaysia especially ILP-KL on personal knowledge management colours of their apprentices and institution. This study aspires to assist such institutions with the practicality of personal knowledge management as to keep on excelling in churning wholesome, competent and dynamic apprentices and technical workforce that is capable of managing their personal knowledge to their best advantage in meeting Malaysia's need for highly competent workforce in threading the future. 
This study aims to identify the Personal Knowledge Management (PKM) capability and compare differences regarding the Personal Knowledge Management (PKM) capability of apprentices in a Technical and Vocational Education and Training (TVET) Institute in Malaysia.

\section{Research Method}

This study had embarked on a quantitative approach using survey to collect data. The Institut Latihan Perindustrian Kuala Lumpur (ILP-KL) was chosen as the place of study due to its maturity and long existence in Malaysia's TVET landscape. ILP-KL is a government or public training organization that implements Malaysia's TVET system and provides technical and craftsmanship training and certification for Malaysian youth in preparing them for employment in Malaysian industries (Economic Planning Unit-Prime Minister's Department, 2015). A sample of 234 apprentices in ILP-KL was taken and questionnaires were distributed to the selected respondents. Questionnaires were pretested and validated and pilot test were conducted to ensure quality of the instruments. The questionnaire items were designed on a 1 (strongly disagree) to 5 (strongly agree) Likert scale. Data gathered from the survey was analyzed using the Statistical Package for the Social Sciences (SPSS) application. For data analysis, descriptive statistics include frequency, percentage, mean and standard deviation while the inferential statistics include the nonparametric test using the Kruskal-Wallis Test and Mann-Whitney $U$ Test.

\section{Findings and Discussion}

\subsection{Profile of Respondents}

The distribution of respondents by gender indicates that majority (207 or $88.5 \%$ ) of the respondents are male and $27(11.5 \%)$ are female. Majority $(228$ or $97.4 \%)$ of the respondents are Malay, $5(2.1 \%)$ are Indian while only $1(0.4 \%)$ is specified as others. There is no Chinese race within the 234 respondents. The highest number of respondents of $191(81.6 \%)$ belongs to the 16-20 years age group followed by $41(17.5 \%)$ in the $21-25$ years age group and only 2 $(0.9 \%)$ are in the 26 and above age group. There are 3 regions in the country that are grouped to represent the arrangement of 14 states of respondents' origin in this study. The respondents' origin centered within states in the vicinity of mid Malaysia (Centre) that accounts to 151 (64.5\%) respondents. Forty-six (19.7\%) are from the North while $37(15.8 \%)$ are from the Southern states. Almost a quarter ( 57 or $24.4 \%$ ) of the respondent are in the lowest level of education level (PMR), 93 (39.7\%) respondents are with SPM/SPVM education level and $84(35.9 \%)$ respondents are from the highest level of education (STPM/SKM3) in ILP-KL.

\subsection{Perception on Personal Knowledge Management Capability}

This section of the data analysis presents the results on the perceptions of 234 respondents in the study on Personal Knowledge Management Capability. The statements on perceptions on respondents in this dimension were measured on a Likert scale of 1 to 5 where the measurement or rating descriptions are as follows: 1 - Strongly Disagree, 2 - Disagree, 3 Quite Agree, 4 - Agree, 5 - Strongly Agree. 
Table 1. Mean Score for Personal Knowledge Management Capability (PKMC)

\begin{tabular}{|c|c|c|c|}
\hline & Statements & Mean & Std. Dev \\
\hline 1 & Can enhance / improve the way knowledge and learning is managed & 4.09 & 0.786 \\
\hline 2 & $\begin{array}{l}\text { All the effort practiced and geared in to manage knowledge assist } \\
\text { study, assignments, practical works etc at ILP }\end{array}$ & 3.95 & 0.795 \\
\hline 3 & $\begin{array}{l}\text { Knowledge acquired enables knowledge enrichment / addition } \\
\text { through further references / discussions / search made }\end{array}$ & 3.91 & 0.729 \\
\hline 4 & $\begin{array}{l}\text { Able to distinct and relate all knowledge to relevant knowledge } \\
\text { concepts }\end{array}$ & 3.90 & 0.692 \\
\hline 5 & $\begin{array}{l}\text { Able to use acquired knowledge to evaluate and understand other } \\
\text { opinion and understanding }\end{array}$ & 3.87 & 0.684 \\
\hline 6 & $\begin{array}{l}\text { Refer back to all knowledge notes / records that have been made and } \\
\text { updated }\end{array}$ & 3.87 & 0.726 \\
\hline 7 & Satisfied with ways in managing knowledge and learning & 3.86 & 0.757 \\
\hline 8 & Easy to acquire knowledge in study & 3.85 & 0.727 \\
\hline 9 & $\begin{array}{l}\text { Update all notes / records on knowledge enrichment / addition that } \\
\text { are acquired }\end{array}$ & 3.81 & 0.746 \\
\hline & Overall mean for PKMC & 3.901 & 0.738 \\
\hline
\end{tabular}

Table 1 indicates an overall mean of 3.901 and standard deviation of 0.738 of Personal Knowledge Management Capability (PKMC) statements which represents the capability of respondents in embracing PKM. The highest mean score of 4.09 is for respondents' perception on the statement that they can enhance and improve the way knowledge and learning is managed. Respondents almost agree that all the effort practiced and geared in to manage knowledge assisted them in their study, assignments, practical works and others at ILP-KL (mean=3.95). The PKMC dimension also demonstrates a mean range of 4.09 to 3.81 . The range gap is quite close and this indicate that respondents are firm at agreeing and leaning more towards agreeing with statements in this dimension. The lowest mean score is 3.81 on the statement that respondents update all notes and records on knowledge enrichment or addition they made or acquired. On an overall basis, respondents indicate that they are capable to flex personal knowledge management.

\subsection{Reliability Test-Cronbach's Alpha}

The first imperative test that was conducted in this study was the reliability test of research variables. The Cronbach's Alpha coefficient test was conducted to conclude the regularity and irregularity of the Likert scale used in the Personal Knowledge Management Capability (PKMC) variable as to indicate the scale reliability used in this study. The result shows that the reliability coefficient for Performance Knowledge Management capability (PKMC) is $\operatorname{good}(\alpha=0.838)$. 


\section{Macrothink}

\subsection{Normality Test - Shapiro-Wilk Test}

The second imperative test that was conducted in this study was the normality test of research variables. The test was conducted to conclude the distribution of data in the Personal Knowledge Management Capability (PKMC) variables as to indicate whether the data were normally distributed or not.

In this study, the Shapiro-Wilk Test was used to assess the data distribution in this study. The results on normal and non normal distribution are guided by the $p$-value, if results are $<0.05$ the data are not normally distributed and if data are $>0.05$ the data are normally distributed. The result of data distribution for PKMC shows a $p$-value of 0.044 thus a nonparametric test was employed.

\subsection{Comparing Personal Knowledge Management Capability (PKMC) among Demographic Groups}

This part of the analysis presents the inferential analysis on comparing Personal Knowledge Management Capability (PKMC) among selected demographic groups of gender, age group, region group and education level group. The nonparametric statistical tests were used in the analysis namely Mann-Whitney $U$ Test and Kruskal Wallis Test as it involved two groups and more than two groups of respondents.

\subsubsection{Differences Regarding PKMC between Male and Female}

Table 2 shows the summary statistics of Mann-Whitney $U$ Test that was undertaken to infer and elaborate male and female respondents' perception on Personal Knowledge Management Capability (PKMC). The test indicated that the z-value of PKMC at -0.385 is not significant at $5 \%$ level $(\mathrm{p}=-0.700>0.05)$ therefore gender do not differentiate the respondents perception on Personal Knowledge Management Capability (PKMC).

Table 2. Summary statistics of Mann-Whitney U Test on PKMC among male and female

\begin{tabular}{lllllll}
\hline Item & $\begin{array}{l}\text { Mean } \\
\text { Male }\end{array}$ & Rank & $\begin{array}{l}\text { Mean } \\
\text { Female }\end{array}$ & Rank & $\begin{array}{l}\text { Mann } \\
U\end{array}$ \\
\hline PKMC & 118.11 & & 112.80 & 2667.500 & -0.385 & phitney \\
& & & & & & z-value \\
\hline
\end{tabular}

*Significant at 0.05 .

\subsubsection{Differences Regarding PKMC among Age Group}

Table 3 shows the summary statistics of Kruskal-Wallis Test that was undertaken to infer and elaborate respondents' difference on the perception of Personal Knowledge Management Capability (PKMC) in respect to age group. The test shows that the significant level of all age group in PKMC is at $5 \%$ level $(\mathrm{p}=0.00<0.05)$ which indicated that there is significant difference of perception on PKMC among respondents in different age group. The mean rank outlined the groups in order with age group 26 and above projecting top with a mean rank of 215.25 , followed by age group 21-25 with mean rank of 155.04 and age group 16-20 with 


\section{Macrothink}

International Journal of Learning and Development

ISSN 2164-4063 2018, Vol. 8, No. 1

108.42. This indicated that the perception on PKMC is greater in the age group of 26 and above and lessens in age group 21-25 and age group 16-20.

Table 3. Summary statistics of Kruskal-Wallis Test on PKMC among respondents with different age group

\begin{tabular}{ll}
\hline Test Statistics & Personal Knowledge Management Capability (PKMC) \\
\hline Mean Rank: 16-20 & 108.42 \\
Mean Rank: 21-25 & 155.04 \\
Mean Rank: 26 and above & 215.25 \\
Chi-Square & 20.324 \\
p-value & 0.00 \\
\hline
\end{tabular}

*Significant at 0.05 .

\subsubsection{Differences Regarding PKMC among Region of Origin}

Table 4 shows the summary statistics of Kruskal-Wallis Test that was undertaken to infer and elaborate respondents' difference on the perception of Personal Knowledge Management Capability (PKMC) from the perspective of respondents' region of origin. The test shows that the analysis result is not significant at $5 \%$ level $(p=0.953>0.05)$. It is concluded that there is no adequate evidence to prove that there is significant difference in the mean score of PKMC measured between respondents of different region of origin.

Table 4. Summary statistics of Kruskal-Wallis Test on PKMC among respondents in different region of origin

\begin{tabular}{ll}
\hline Test Statistics & Personal Knowledge Management Capability (PKMC) \\
\hline Mean Rank: North & 114.73 \\
Mean Rank: Center & 118.18 \\
Mean Rank: South & 118.16 \\
Chi-Square & 0.097 \\
p-value & 0.953 \\
\hline
\end{tabular}

*Significant at 0.05 .

\subsubsection{Differences Regarding PKMC among Education Level}

Table 5 shows the summary statistics of Kruskal-Wallis Test that was undertaken to infer and elaborate respondents' difference on the perception of Personal Knowledge Management Capability (PKMC) from education level angle. The test shows that analysis result is not significant at $5 \%$ level $(p=0.121>0.05)$. 


\section{Macrothink}

International Journal of Learning and Development

ISSN 2164-4063 2018, Vol. 8, No. 1

Table 5. Summary statistics of Kruskal-Wallis Test on PKMC among respondents with different education level

\begin{tabular}{ll}
\hline \multicolumn{1}{l}{ Test Statistics } & Personal Knowledge Management Capability (PKMC) \\
\hline Mean Rank: PMR & 125.17 \\
Mean Rank: SPM/SPVM & 106.33 \\
Mean Rank: STPM/SKM3 & 124.66 \\
Chi-Square & 4.225 \\
p-value & 0.121 \\
\hline
\end{tabular}

*Significant at 0.05 .

\section{Conclusion}

As the conclusion, this study has answered the aim of the study and attained the objective of producing descriptive and inferential analysis on data collected. This study has examined the perception level of respondents on Personal Knowledge Management Capability in Institut Latihan Perindustrian Kuala Lumpur. The findings therefore concluded that, the level of perception on PKMC is positive and moderate. The findings have also led to the notion that ILP-KL has positive room for improvement to be made in its apprentices' personal knowledge management activity.

The results of the study indicate that all the variables in the framework were positively rated by the respondents. This also indicate that apprentices perceived positively the Personal Knowledge Management Enabler dimensions and Personal Knowledge Management Capability therefore the framework developed in this study is considered firm and fitting to be referred and used. The results and findings also conformed to the theory put forward by Jafari, Akhavan and Nikookar (2013) based on the best of Frand and Hixon (1999) and Avery et al. (2001) description of PKMs' seven processes that denote individual or personal activities related to knowledge retention, retrieval and utilization in managing knowledge. Therefore the framework that was developed and used in this study is firm in its footing.

This study was executed in conformance to study requirements and planning although there were some limitations encountered by the researcher. However the limitations have been thoroughly considered and mitigated as to avoid disruptions to the research. The limitations and mitigations are as follows:

1) The study was conducted at Institut Latihan Perindustrian Kuala Lumpur (ILP-KL) although the whole network of ILPs amounted to 25 institutes which are located all over Malaysia. It was not possible for the researcher to cover all institutes in the timeframe available. As ILP-KL is the main institution in Kuala Lumpur, the ILP is with most apprentices among all other ILP therefore the institution was chosen for practicality purposes.

2) The TVET ecology is huge in Malaysia; it comprises apprentices, ministries, government agencies, institutions, related private organization and institutions, and the industries. The subject of TVET also comprises a very broad continuum of academic, management and 
pedagogical aspects and it is beyond means of the researcher to embarked studies that warranted collaboration of entities on bigger scale, therefore the researcher has mitigated for a study to be made based on his limit of execution, professional experience and postgraduate learning interest which is Personal Knowledge Management (PKM).

This study will provide the management, lecturers and trainers with the current standing of their apprentices in personal knowledge management. Detailed analyses and description on how the apprentice fares in dimensions of Knowledge Concepts Awareness (KCA), Knowledge Retention Practice (KRP) and Knowledge Retrieval-Utilization Practice (KRUP) will be rendered to ILP-KL thus enabling the management and its driving force to picture and gauge their apprentices ability and capability in the said areas. The Personal Knowledge Management Capability (PKMC) dimension would also be able to provide a simple report on the apprentices and institution's health. Most important of all the study results will be able to provide the platform and points for the management and its drivers to communicate through discussions, workgroups, counselling, student advisory etc. with apprentices in the effort to guide apprentice to be better in their learning at the institution.

On a larger scale, this study will provide ILP-KL, its institution network, other similar institutions and possibly the country's TVET drivers' with an academically tested framework of Personal Knowledge Management. The framework provided would help TVET institutions in developing further its apprentices' knowledge management capability and skills in managing day to day technical learning that they endured. The framework would also help TVET institutions management, lecturers and trainers to gain insights on apprentices' knowledge management behaviour and practices as to develop breakthrough knowledge management policies, strategies and techniques that would alleviate apprentices' competencies to the next level. In this sense, the framework of the study focuses on the Personal Knowledge Management Enabler and Personal Knowledge Management Capability of which the dimensions of Knowledge Concepts Awareness, Knowledge Retention Practice, Knowledge Retrieval-Utilization Practice and Personal Knowledge Management Capability has been modelled to be practical for any implementation of knowledge management initiatives.

The findings from this study have also enabled the researcher to provide feedbacks, empirical standings, recommendations and suggestions to both ILP-KL and institutions alike such as repeat similar study on larger respondent sample at ILP-KL, repeat study in ILP-KL or any organizations with expansion of the PKME dimensions, extend similar study to other regional or state ILPs and the approach may be implemented on a mix method of qualitative and quantitative angle in moving forward to initiate effective PKM capability development activities, programs or projects.

\section{Acknowledgement}

The authors wish to thank all respondents who had participated in the survey.

\section{References}

Avery, S., Brooks, R., Brown, J., Dorsey, P., \& O'Conner, M. (2001). Personal knowledge 
management: Framework for integration and partnerships. Paper presented at 35th Annual Conference of the Association of Small Computer Users in Education (ASCUE), Myrtle Beach, SC, 11-14 June.

Davenport, T. H. (1994). Saving IT's soul: Human centered information management. Harvard Business Review, 72(2), 119-131.

Duhon, B. (1998). It's all in our heads. Inform, 12(8), 8-13.

Amin, F. N., \& Ruhizan, M. (2014). Learning transfers in training institutions and the workplace in Malaysia. Online Journal for Technical and Vocational Education and Training in Asia, 3(3), 1-16. Retrieved from http://www.tvet-online.asia/issue3/yunus_yasin_tvet3.pdf.

Frand, J., \& Hixon, C. (1999). Personal knowledge management: Who, what, why, when, where, how? Working paper. Retrieved from http://www.anderson.ucla.edu/faculty/jason.frand/researcher/speeches/PKM.htm

Jafari, M., Akhavan, P., \& Nikookar, M. (2013). Personal knowledge management and organization's competency: A service organization case study. Education, Business and Society: Contemporary Middle Eastern Issues, 6(3/4), 181-194. https://doi.org/10.1108/EBS-08-2012-0036

Kassim, N. A., Baharuddin, M. F., \& Samad, Z. A. (2016). Knowledge management practices and organizational performance in Malaysian government institution. International Journal for Informics, 9(4), 1233-1238.

Li, G., \& Li, Y. (2009). A study on blog based personal knowledge management. Second International Workshop on Knowledge Discovery and Data Mining. 248-251. https://doi.org/10.1109/WKDD.2009.166

Farshad, M., \& Azizi, G. (2015). Relationship of team learning with knowledge management in second grade high school teachers in Saveh city. International Journal of Learning and Development, 5(4), 1-12. https://doi.org/10.5296/jsr.v6i2.8577

Martins, E. C., \& Meyer, H. W. J. (2012). Organizational and behavioral factors that influence knowledge retention. Journal of Knowledge Management, 16(1), 77-96. https://doi.org/10.1108/13673271211198954

Satar, S. (2012). Exploring knowledge management practices. International Journal of Learning and Development, 2(1), 330-352. https://doi.org/10.5296/ijld.v2i1.1352

\section{Copyright Disclaimer}

Copyright for this article is retained by the author(s), with first publication rights granted to the journal.

This is an open-access article distributed under the terms and conditions of the Creative Commons Attribution license (http://creativecommons.org/licenses/by/4.0/). 